\title{
Attack of Tunisian Phosphate Ore by a Mixture of Sulfuric and Phosphoric Acid: Thermochemical Study by Means of Differential Reaction Calorimetry
}

\author{
Olfa Lachkar-Zamouri1', Khemaies Brahim ${ }^{1}{ }^{*}$, Feten Bennour-Mrad ${ }^{2}$, Ismail Khattech' \\ ${ }^{1}$ Chemistry Department: LR15ES01 Materials, Cristallochemistry and Applied Thermodynamics Laboratory, Faculty of Science, \\ Tunis El Manar University, Tunis, Tunisia \\ ${ }^{2}$ Direction of Scientific Research, Tunisian Chemical Group, Sfax, Tunisia \\ Email: ^brahimkhemaies@gmail.com
}

How to cite this paper: Lachkar-Zamouri, O., Brahim, K., Bennour-Mrad, F. and Khattech, I. (2018) Attack of Tunisian Phosphate Ore by a Mixture of Sulfuric and Phosphoric Acid: Thermochemical Study by Means of Differential Reaction Calorimetry. Advances in Materials Physics and Chemistry, 8, 411-427.

https://doi.org/10.4236/ampc.2018.810028

Received: September 18, 2018

Accepted: October 23, 2018

Published: October 26, 2018

Copyright $\odot 2018$ by authors and Scientific Research Publishing Inc. This work is licensed under the Creative Commons Attribution International License (CC BY 4.0).

http://creativecommons.org/licenses/by/4.0/

\begin{abstract}
A calorimetric, Differential Reaction Calorimetry (DRC), study of the thermochemical of the attack of a phosphate ore from Gafsa region (Tunisia) by a mixture of sulfuric and phosphoric acid is undertaken at different solid-liquid ratio and different temperature. The plot of the quantity of heat measured by integrating the raw signal as a function of the dissolved mass in the same volume solution at $25^{\circ} \mathrm{C}$ presents three straight segments attributed at the formation of the hemihydrate $\left(\mathrm{CaSO}_{4} \cdot 1 / 2 \mathrm{H}_{2} \mathrm{O}: \mathrm{HH}\right)$, the dihydrate $\left(\mathrm{CaSO}_{4} \cdot 2 \mathrm{H}_{2} \mathrm{O}: \mathrm{DH}\right)$ or a mixture of these two products checked by X-ray diffraction, infrared spectroscopy and thermal analysis (Differential Scanning Calorimeter: DSC). The attack by the acid mixture was performed at higher temperature and showed in addition the formation of another form of calcium sulfate:anhydrous $\left(\mathrm{CaSO}_{4}: \mathrm{AH}\right)$. Moreover, the variation of mass enthalpy versus temperature presents a break at the $\mathrm{T}=45^{\circ} \mathrm{C}$. According to our results, it seems that the effect of the temperature on the sulfo-phosphoric attack reaction on the natural phosphate (NP) generates a change of mechanism at around $45^{\circ} \mathrm{C}$.
\end{abstract}

\section{Keywords}

Dissolution, Thermochemistry, Differential Reaction Calorimeter, Phosphate Ore, Liquid/Solid, Temperature

\section{Introduction}

Phosphates, in the form of fertilizers, are essential in the agricultural sector [1] 
[2]. They are also very important constituents in animal feed stocks and in food and other chemical industries. Phosphate ore is an important economic deposit in Tunisia since it represents one of the most important resources of currency. It is classified as high quality ores varied their $\mathrm{P}_{2} \mathrm{O}_{5}$ cotenants of $26 \%-35 \%$ of $\mathrm{P}_{2} \mathrm{O}_{5}$. The phosphate ore used for manufacturing fertilizers are mainly sedimentary [3] [4] [5] essentially composed of fluorapatite (FAP) containing various proportions of other compounds of calcium, fluorine, iron, aluminum, quartz, les silicates and metal oxides [6] [7]. The composition of phosphate rocks varies from one deposit to another and therefore phosphate rocks from different sources are expected to behave differently in acidulation processes [8].

It is well know that natural phosphates cannot be used directly as a fertilizer because of their insolubility to make them available to plants, phosphate are dissolved by acids. A number of published studies devoted to phosphate synthetic [9]-[16] or natural [17]-[37] in single aqueous acid solutions were carried such as phosphoric acid [10] [11] [12] [13] [21] [22] [23], succinic acid [24], nitric acid [28] and hydrochloric acid [9] [13] [26] [27] or mixture acid solution [33] [34] [35] [36] in literature to clarify the kinetics and process mechanism and improve the performance of phosphate attack. However, phosphate rocks decomposition by sulfuric acid remains the most widely used method [29] [30] [21] [32] and over $90 \%$ of the phosphoric acid produced worldwide is manufactured by digestion of phosphate rocks with sulfuric acid as an acidulant [37].

The techniques used in the majority of published studies devoted to kinetics and thermodynamic reaction these works were ICP [38], isoperibolic calorimetry [39] and microscopy [10]. These techniques, however, do not allow the accurate tracking of the natural phosphate (NP) attack process over time. There are other techniques that provide more accurate information about what happens in situ, such as microcalorimetry and Differential Reaction Calorimetry (DRC).

DRC is not widely used. In fact, only some works in our team have used this technique. Amira et al. [20] [23] used a SETARAM calorimeter DRC to study the kinetic and thermodynamic aspects of the dissolution of Tunisian phosphate ore by 25 mass $\% \mathrm{P}_{2} \mathrm{O}_{5}$ of phosphoric acid in the range $25^{\circ} \mathrm{C}$ to $65^{\circ} \mathrm{C}$. The results found that the attack rate of Tunisian phosphate ore by phosphoric acid increased with increasing temperature and the kinetic results agree with the shrinking-core model with an ash layer diffusion control. The resulting apparent activation energy equals $25.4 \pm 1.8 \mathrm{~kJ} \cdot \mathrm{mol}^{-1}$. In the same context, another study was carried out by Brahim et al. [13] to investigate the attack of a Fap in the hydrochloric acid solution showed that the dissolution kinetics was examined according to the heterogeneous reaction models and proved that the dissolution is controlled by the product layer diffusion process.

Regardless of the technique used, the performance of the NP attack reaction is not always satisfactory. For example, at the Tunisian industrial scale (SIAPE), the loss of $\mathrm{P}_{2} \mathrm{O}_{5}$ is $4 \mathrm{~g}$ per $\mathrm{kg}$ of phosphogypsum. To reduce the cost of production and meet an increasing demand for phosphate products while remaining 
competitive, the Tunisian phosphate industry needs to improve this yield or to revise the reaction of the acid attack on phosphate ores. The present paper aims at the use of a calorimetric approach for the determination of thermodynamic parameters of a solid dissolution with a chemical reaction. The idea is to study the effect of the factors affecting the reaction efficiency of the acid attack on the phosphates such as solid-liquid ratio and the temperature.

\section{Material and Method}

Phosphates rocks were obtained from a mine located at Gafsa (Tunisia). It was supplied by the manufacture CPG (Company of Phosphate from Gafsa). The chemical composition determined by Amira et al. [23] involve thermogravimetry (B60 SETARAM microbalance), ionometry using a specific fluoride electrode ISE25F and $\mathrm{Ag} / \mathrm{AgCl}$ reference electrode and inductively coupled plasma (ICP).

The DRC used is a SETARAM model which works based on the simple principle of differential thermal analysis which continuously measures a temperature difference, $\Delta \mathrm{T}$, between a measuring reactor and a reference one. The reliability of this apparatus for kinetic and thermodynamic studies has been intensively researched by Amira et al. [20] [23] [40]. The experimental protocol followed to study the dissolution of the NP in the sulfo-phosphoric mixture can be described as follows: $100 \mathrm{~g}$ of the attacking solution, $\mathrm{S},(20 \mathrm{~g}$ of concentrated sulfuric acid and $80 \mathrm{~g}$ of recycled phosphoric acid, $20 \%$ of $\mathrm{P}_{2} \mathrm{O}_{5}$ ) and a mass " $\mathrm{m}$ " of the NP in a sealed sample holder which prevents its contact with the attacking solution were placed in the measuring reactor. To keep things balanced, the same amount of reactants was placed in the reference reactor. The contact of the two reagents is triggered by opening the sample holder. Some time, which varies according to the kinetics of the phe11nomenon, is necessary to regain thermal equilibrium which is seen by the return to the baseline. A calibration operation is then carried out by recreating in the measuring cell a power close to that produced by the chemical phenomenon studied for a variable period of time. The same calibration operation is also performed before the NP attack. These two operations are necessary in order to determine the specific heat of the mixture obtained before and after dissolving the NP (Figure 1).

\section{Experimental Results}

\subsection{Effect of the Solid/Liquid Ratio}

The dissolution of NP was performed several times by progressively increasing the mass of solid dissolved in the same volume of solvent ( $100 \mathrm{~g})$. The thermogenesis was calculated from the knowledge of the parameters of the transfer function, determined in situ after each dissolution experiment for any mass of NP dissolved, and two peaks were obtained for the same concentration of acid at a temperature of $25^{\circ} \mathrm{C}$ (Figure 2). However, the representation of the heat variation, $\mathrm{Q}$, measured by integrating the crude calorimetric signal as a function of the mass of phosphate dissolved in the solution S, seems to be linear and sug- 
gests that the same phenomenon is taking place (Figure 3). But the analysis of the solid residue obtained by filtration following each X-ray diffraction attack using Ka radiation, with a wavelength $\lambda=1.54051 \AA$ emitted by a copper anticathode, infrared spectroscopy and thermal analysis (Differential Scanning Calorimeter: DSC) show the formation of the hemihydrate $\left(\mathrm{CaSO}_{4} \cdot 1 / 2 \mathrm{H}_{2} \mathrm{O}: \mathrm{HH}\right)$, the dihydrate $\left(\mathrm{CaSO}_{4} \cdot 2 \mathrm{H}_{2} \mathrm{O}: \mathrm{DH}\right)$ or a mixture of these two products. Dihydrate is often called phosphogyps, it can retain in its structure a quantity of phosphate up to $2 \%$ weight of $\mathrm{P}_{2} \mathrm{O}_{5}$ [41]. Thus, three zones have been defined and labeled respectively as zone " 1,2 and 3 " (Figure 3 ), each one of them corresponding to the dissolution of the NP followed by the precipitation of one of these solids or a mixture of two of them.

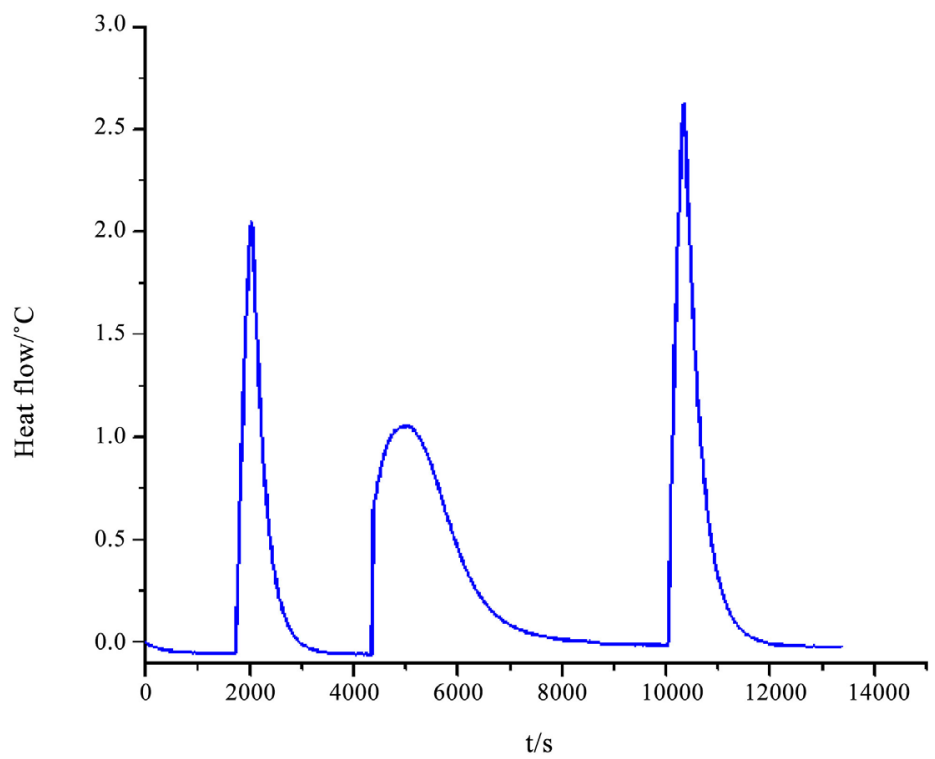

Figure 1. Example of one of the DRC curves recorded.

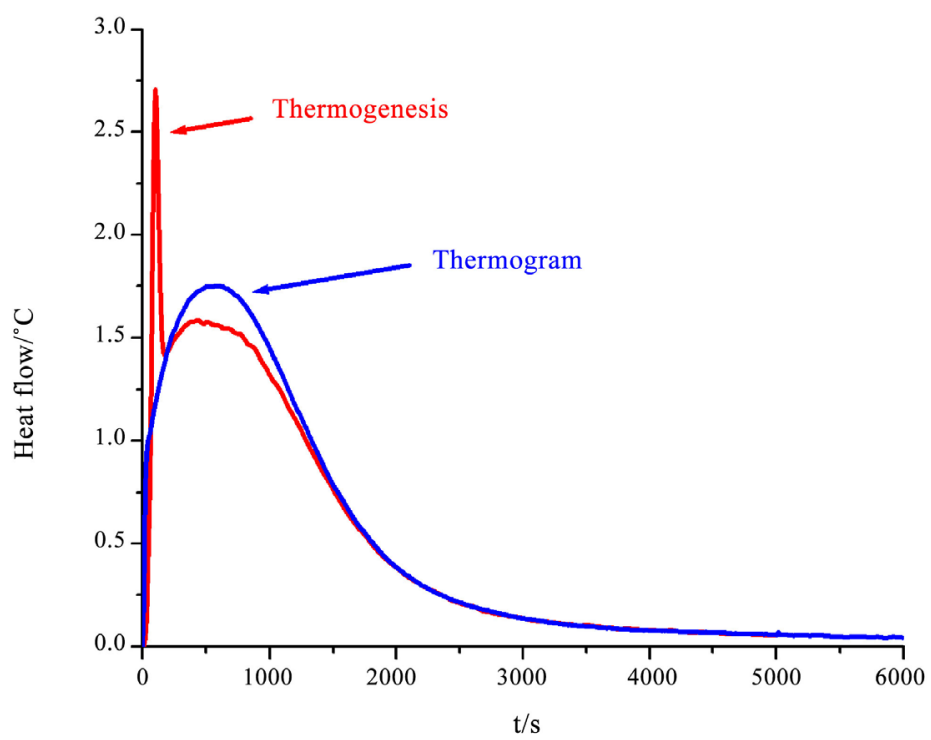

Figure 2. Deconvoluted curves for the different NP masses at a temperature of $25^{\circ} \mathrm{C}$. 


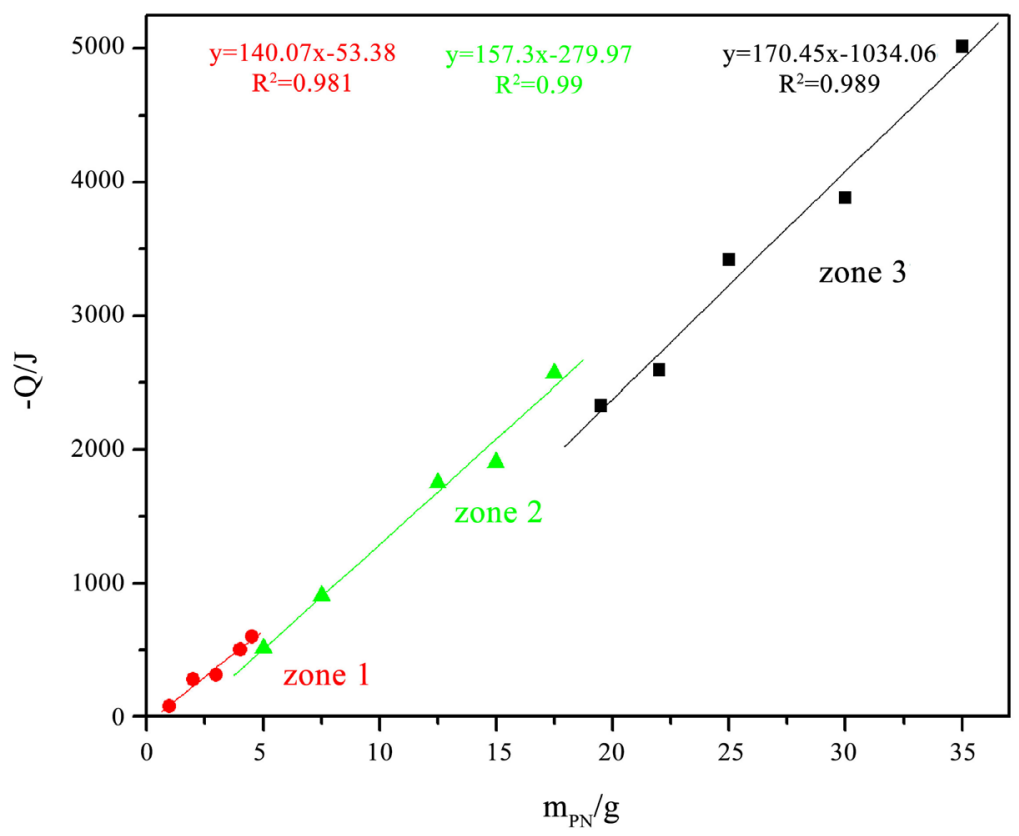

Figure 3. Total enthalpy as a function of mass of the NP.

\section{“Zone 1"}

This zone is defined for the lightest masses of the solid ( $\mathrm{m} \leq 5 \mathrm{~g}$ ) dissolved in solution $\mathrm{S}$. The second peak observed on the thermogenesis graph has been attributed to the precipitation of the HH. This is deduced from the results of the $\mathrm{X}$-ray diffraction (Figure 4) and the IR spectroscopy (Figure 5) carried out on the solid recovered from the NP attack. Indeed, the IR spectrum obtained is characteristic of $\mathrm{HH}$ and only shows two vibrational bands at about $3700-3500$ $\mathrm{cm}^{-1}$ corresponding to the valence vibration of $\mathrm{O}-\mathrm{H}$ of the water molecule, and a single deformation mode of $\mathrm{H}_{2} \mathrm{O}$ at around $1620 \mathrm{~cm}^{-1}$ and which can be attributed to this product [42].

The gradient of the straight line obtained in this zone makes it possible to calculate a mass enthalpy $\Delta H=-140 \mathrm{Jg}^{-1}$ of NP attacked.

However, in an earlier work by Antar et al. [14] for low phosphate ratios at $25^{\circ} \mathrm{C}$, the precipitation of dihydrate was perforated whereas in the present work we have found the hemihydrate. This finding may be justified by the time of the attack reaction (longer time: five hours) which favors the transformation of $\mathrm{HH}$ into $\mathrm{DH}$. This last observation is confirmed in another work by these authors [15] at higher temperatures $\left(\mathrm{T}=55^{\circ} \mathrm{C}\right)$.

\section{"Zone 2"}

This zone is defined by NP masses in the range $5 \mathrm{~g} \leq \mathrm{m} \leq 18 \mathrm{~g}$. The value of the gradient of the line segment $(-\Delta \mathrm{H}=\mathrm{f}(\mathrm{m}))$ in this zone shows an increase with respect to zone $1\left(\Delta H=-157.3 \mathrm{Jg}^{-1}\right)$. This result is probably due to the precipitation of the dihydrate $\left(\mathrm{CaSO}_{4} \cdot 2 \mathrm{H}_{2} \mathrm{O}: \mathrm{DH}\right)$ next to the $\mathrm{HH}$. The presence of these two solids was shown by the X-ray diffraction and IR spectroscopy performed on the residue obtained after the attack (Figure 4 and Figure 5). Indeed, for the IR spectrum, a new band was seen to appear at around $3400 \mathrm{~cm}^{-1}$ which 
is characteristic of the valence vibration of the $\mathrm{O}-\mathrm{H}$ of the water molecule in $\mathrm{DH}$ [43]. Similarly, the X-ray diffraction pattern shows the appearance of the characteristic lines of $\mathrm{DH}$ [44]. The quantitative analysis of the characteristic peak of $\mathrm{DH}$ showed that the latter increases with the NP mass. This is deduced by comparing the intensity ratio characteristic of peak 14 of $\mathrm{HH}$ and peak $11 \mathrm{of} \mathrm{DH}$. Indeed, this comparison was used by Valimbe et al. to obtain quantitative information on the coexistence of these two phases [45]. Thus, the second peak of the thermogenesis calculated in this zone was attributed to the precipitation of these two products.

$\square \mathrm{DH}$

$\mathrm{O} \mathrm{HH}$

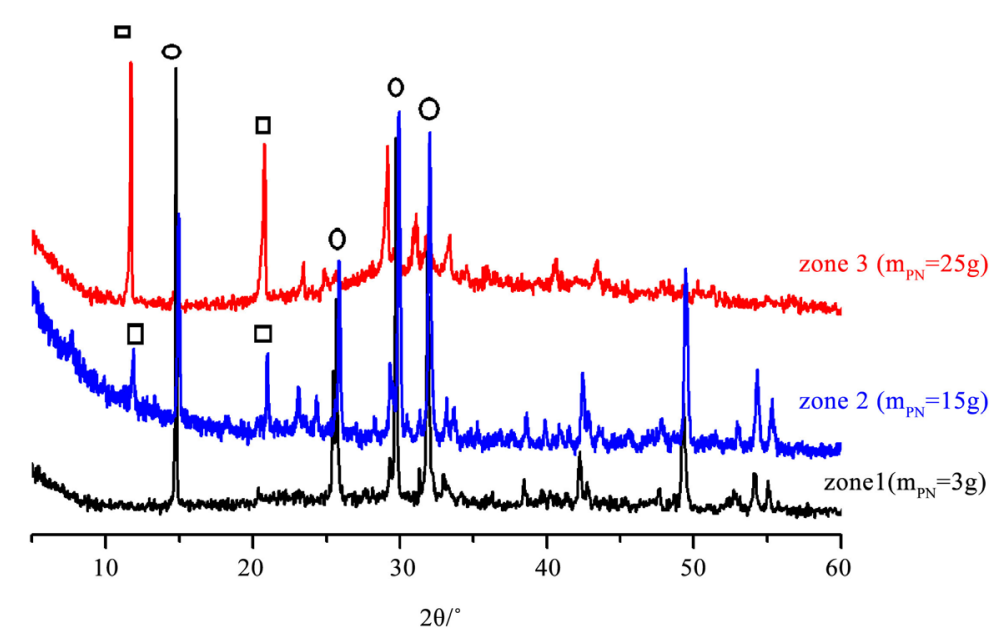

Figure 4. Diffractograms recorded of the residue obtained after attack for different NP masses.

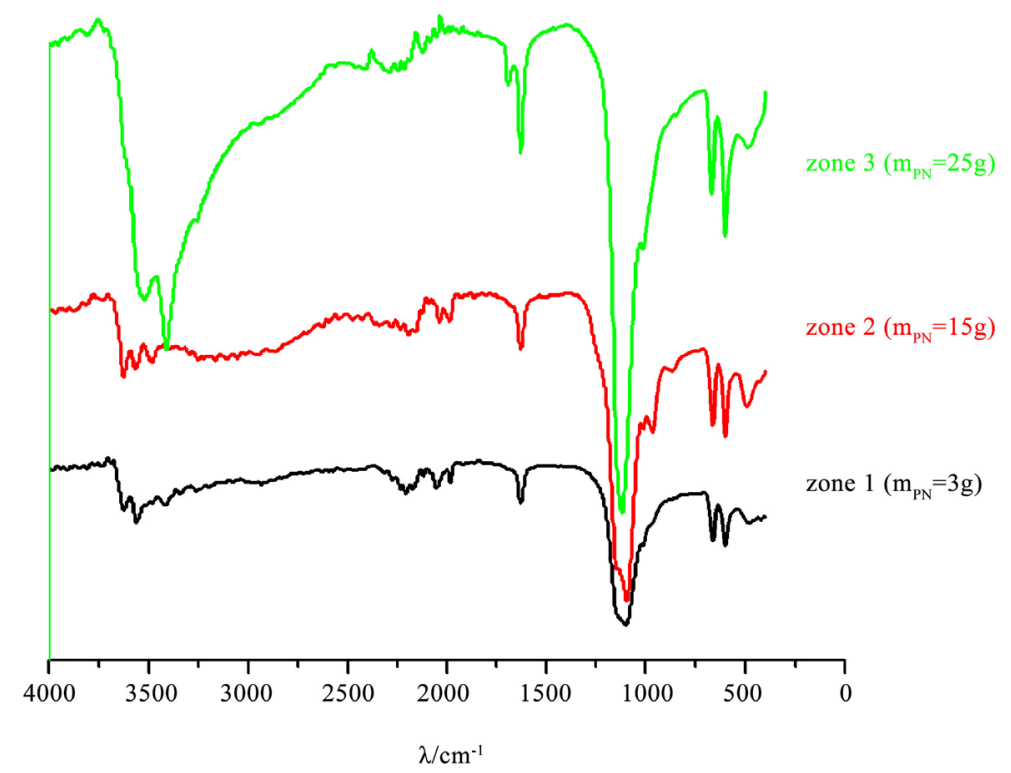

Figure 5. IR spectra recorded of the residue obtained after attack for different NP masses. 


\section{"Zone 3"}

This zone contains the industrial conditions for the production of phosphoric acid adopted by the CPG. It is defined for masses greater than $18 \mathrm{~g}$. In this zone the precipitate consists essentially of $\mathrm{DH}$. The thermogenesis calculated in this zone is formed by two peaks: the first peak is attributed to the dissolution of the NP while the second one is attributed to the precipitation of the DH.

To corroborate the XRD and IR results, the thermal analysis was performed for the solid residues obtained in each zone. A SETARAM Differential Scanning Calorimeter was used and the heating rate used in all the experiments was $10^{\circ} \mathrm{C}$ $\mathrm{min}^{-1}$. Figure 6 give the curves a, $\mathrm{b}$ and $\mathrm{c}$ obtained for the solid residues in zone 1,2 and 3 respectively.

The curve (a) shows the presence of two endothermic peaks appearing at $\mathrm{T}=$ $114^{\circ} \mathrm{C}$ and $\mathrm{T}=176^{\circ} \mathrm{C}$, respectively. The first one has been attributed to the moisture water, while the second one has been attributed to the decomposition of the $\beta$-hemihydrate into an anhydrite according to the reaction shown in Equation (1). This result is in agreement with that obtained by R. James et al. [46].

$$
\mathrm{CaSO}_{4} \cdot 1 / 2 \mathrm{H}_{2} \mathrm{O}(\beta) \stackrel{10^{\circ} \mathrm{Cmin}^{-1}}{T=176^{\circ} \mathrm{C}} \mathrm{CaSO}_{4}+1 / 2 \mathrm{H}_{2} \mathrm{O}
$$

The curve (b) also reveals two endothermic effects. The first one appears at a temperature close to $\mathrm{T}=167^{\circ} \mathrm{C}$ and mainly corresponds to 1.5 mole of water per mole of calcium sulfate leaving, i.e. to the reaction described by Equation (2). The second peak at $\mathrm{T}=185^{\circ} \mathrm{C}$ was attributed to the dehydration of $\mathrm{HH}$ (Equation (3)). These observations are in good agreement with similar findings by $\mathrm{El}$ Cadi et al. [47] and Ben Mansour et al. [48].

$$
\begin{aligned}
& \mathrm{CaSO}_{4} \cdot 2 \mathrm{H}_{2} \mathrm{O}(\beta) \underset{T=167^{\circ} \mathrm{C}}{\stackrel{10^{\circ} \mathrm{min}^{-1}}{\longrightarrow}} \mathrm{CaSO}_{4}, 1 / 2 \mathrm{H}_{2} \mathrm{O}(\beta)+3 / 2 \mathrm{H}_{2} \mathrm{O} \\
& \mathrm{CaSO}_{4} \cdot 1 / 2 \mathrm{H}_{2} \mathrm{O}(\beta) \underset{T=\frac{10^{\circ} \mathrm{Cmin}^{-1}}{T=185^{\circ} \mathrm{C}}}{\longrightarrow} \mathrm{CaSO}_{4}(\text { soluble })+1 / 2 \mathrm{H}_{2} \mathrm{O}
\end{aligned}
$$

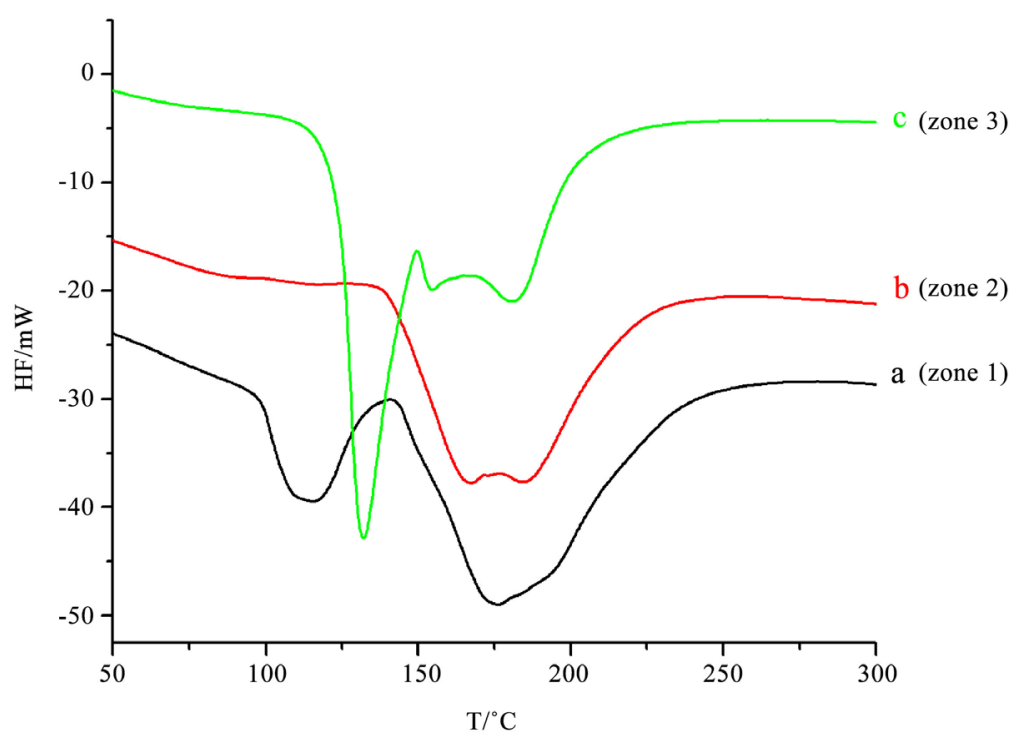

Figure 6. DSC curves obtained for the solid residues after attack for different zones. 
The curve (c) shows the presence of three endothermic peaks occurring at a temperature of $131^{\circ} \mathrm{C}, 153^{\circ} \mathrm{C}$ and $183^{\circ} \mathrm{C}$ respectively. The first peak corresponds to the departure of the 1.5 moles of water from the calcium sulfate dihydrate. The second less intense peak, at around $\mathrm{T}=183^{\circ} \mathrm{C}$, corresponds to the dehydration of the HH into anhydrite sulfate. The results obtained are in a good agreement with those found by L. Violeta et al. [49]. The curve in this zone also reveals another endothermic phenomenon at around $\mathrm{T}=153^{\circ} \mathrm{C}$ and which can be attributed to the dehydration of the $\mathrm{HH}$ initially present in the residue obtained in zone 3. The explanation for this result will be seen later when we study the effect of temperature on the residue obtained after each dissolution.

\subsection{Effect of Temperature on the Dissolution Reaction}

At the industrial scale, the exothermic effect that results from the acid attack reaction on the NP makes it possible to maintain the temperature of the mashed mixture at about $80^{\circ} \mathrm{C}$. In order to obtain conditions close to those used in the industrial context; the attack of the NP by the acid solution was measured at different temperatures in the $25^{\circ} \mathrm{C}-65^{\circ} \mathrm{C}$ range for each of the zones obtained during the solid-liquid ratio study described above. It should be noted that it was not possible to go beyond $65^{\circ} \mathrm{C}$ due to the poor stability of the apparatus at higher temperatures.

The experimental protocol used for this study is the same one adopted previously for a temperature of $25^{\circ} \mathrm{C}$ and described in the study of the effect of the solid-liquid ratio. This ratio was kept constant in each of the zones ( $3 \mathrm{~g}$ for "zone $\mathrm{T} 1$ ", $15 \mathrm{~g}$ for "zone T2" and $25 \mathrm{~g}$ for "zone T3")

"Zone T1"

Figure 7 shows the change in the mass enthalpy $\Delta_{r} H_{\text {mes }}$ calculated by integrating the raw signal as a function of temperature in the range considered. Examining this curve it can be seen that the heat quantity of the sulfo-phosphoric attack reaction undergoes a linear change until it reaches a temperature of about $35^{\circ} \mathrm{C}$ followed by a random change past this temperature. In order to interpret this thermal behavior of the reaction, X-ray diffraction and IR spectroscopy of the solid residues recovered after filtration were performed. The results obtained show that for temperatures $\mathrm{T} \leq 30^{\circ} \mathrm{C}$ the precipitate formed is purely $\mathrm{HH}$. Thus, for this temperature range, the variation of the mass enthalpy follows Kirchhoff's law. However, at higher temperatures, the solid obtained after attack consists of three phases: the dihydrate, the hemihydrate and the anhydrous (AH) (Figure 8 and Figure 9). The analyses performed also show that the anhydrous phase forms at a temperature of about $47^{\circ} \mathrm{C}$. Similar results were previously obtained by A. G. Ostroff et al. study of the conversion of gypsum to anhydrite in aqueous salt solutions [50]. The authors showed that the transformation of the dihydrate into an anhydrous occurs at a temperature of $46^{\circ} \mathrm{C} \pm 2^{\circ} \mathrm{C}$.

"Zone T2"

The curve in Figure 10 shows the change in the mass enthalpy versus temper- 
ature for "zone T2". The shape of this curve suggests the presence of two different chemical phenomena on either side of $45^{\circ} \mathrm{C}$. However, the IR and the X-Ray diffraction analysis show the coexistence of two phases: $\mathrm{HH}$ and $\mathrm{DH}$ in all residues obtained (Figure 11 and Figure 12). These figures also show that the main characteristic lines of DH increase as the temperature increases. This reveals that DH increases with temperature and can thus explain the variation of the enthalpy mass in this zone. These observations are in agreement with the thermal analyses carried out on the residues obtained in the two domains (domain "a" for temperatures lower than $45^{\circ} \mathrm{C}$ and domain " $\mathrm{b}$ " for higher temperatures). Indeed, the DSC curve (Figure 13) obtained in each domains similar to that previously obtained in the study of the effect of the solid-liquid ratio obtained in "zone T2" for a temperature of $\mathrm{T}=25^{\circ} \mathrm{C}$.

"Zone T3"

The mass enthalpy versus temperature is similar to that for "zone T2" (Figure 14). Indeed, the two line segments obtained also have a break at the same temperature $\left(\mathrm{T}=45^{\circ} \mathrm{C}\right)$. This suggests that the same phenomenon occurs in both domains. However, the X-ray diffractograms and the IR spectra obtained for the solids isolated by filtration in this zone show the precipitation of $\mathrm{HH}$ and $\mathrm{DH}$ at a temperature of less than $45^{\circ} \mathrm{C}$, while for higher temperatures only the $\mathrm{DH}$ precipitates (Figure 15 and Figure 16). These results are also corroborated by the thermal analysis of the residues obtained on either side of this temperature (Figure 17). Indeed, for temperatures above $45^{\circ} \mathrm{C}$, the DSC curve is characteristic of the dehydration of $\mathrm{DH}$ alone and the characteristic peak of the dehydration of the hemihydrate, which was initially present, is not observed.

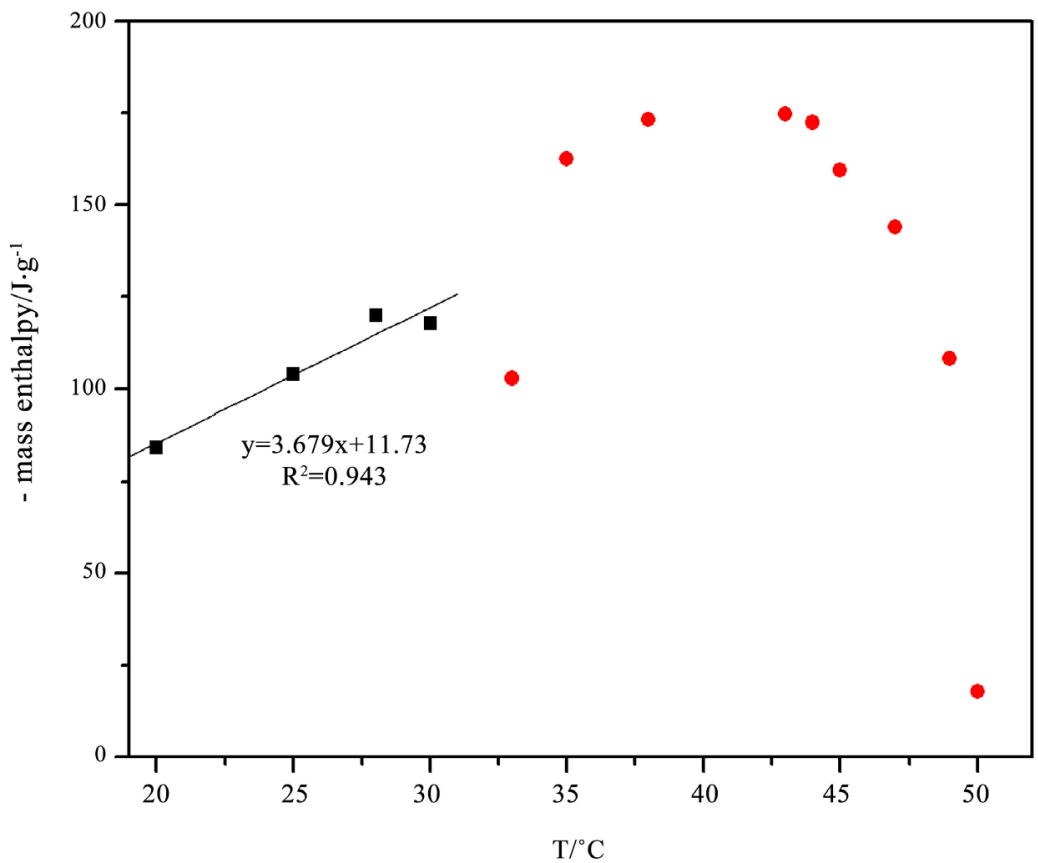

Figure 7. Variation of the mass enthalpy as a function of temperature for the reaction in zone 1 . 


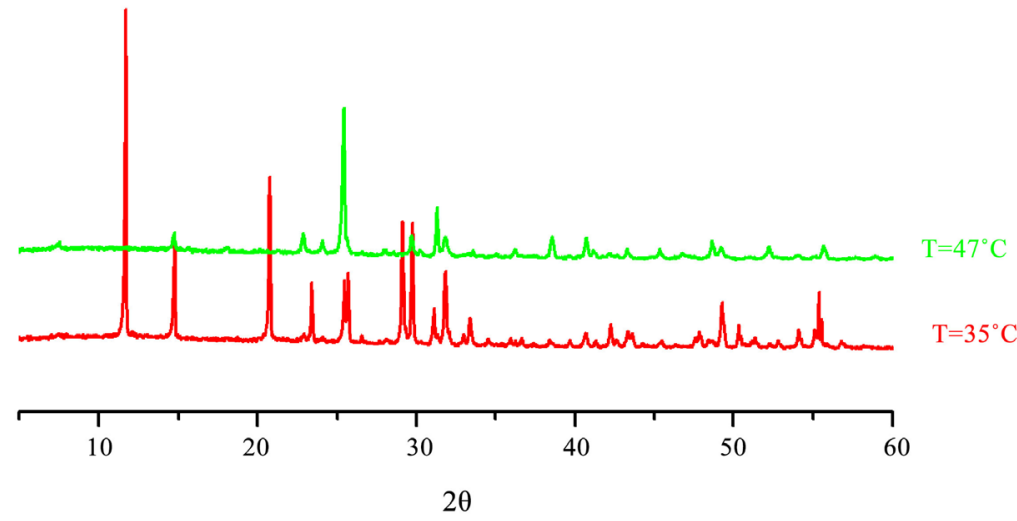

Figure 8. Diffractograms recorded of the residue obtained after attack for the different temperatures in zone 1.

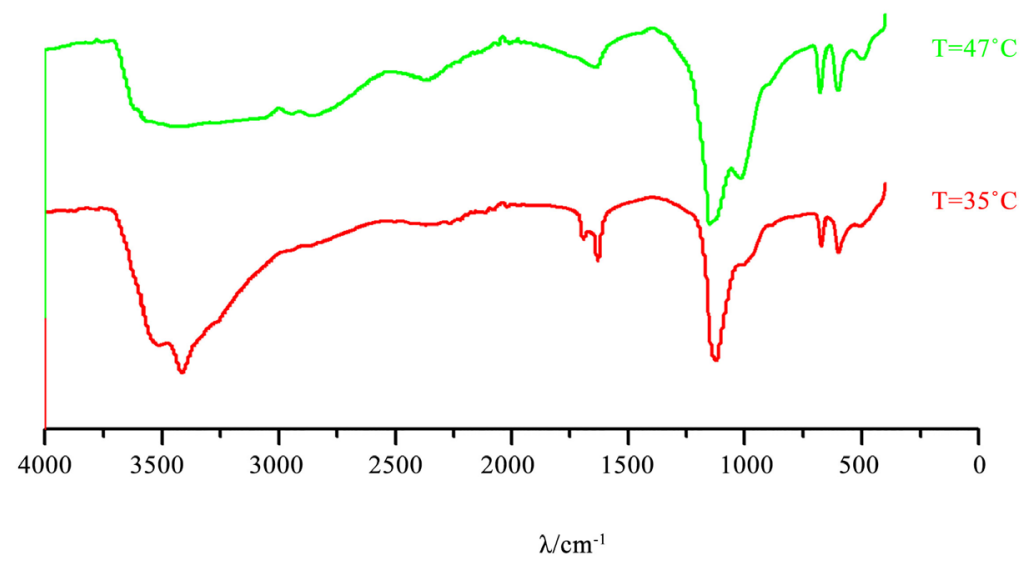

Figure 9. IR spectra recorded of the residue obtained after attack at different temperatures in zone 1.

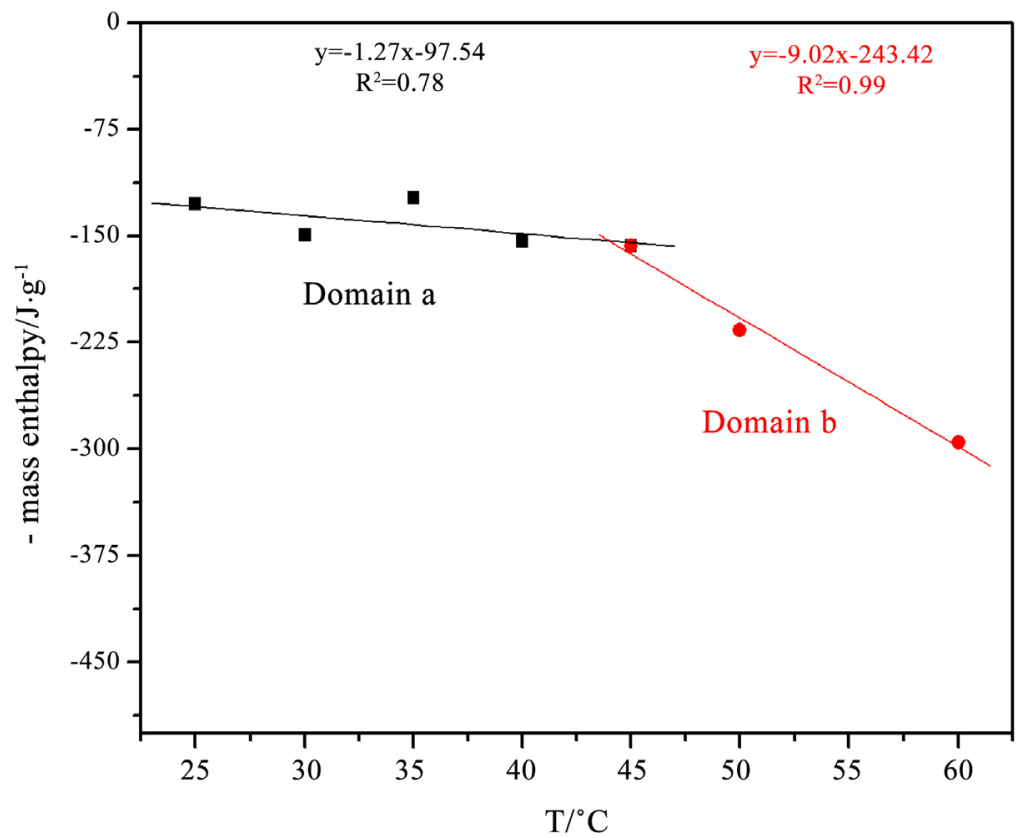

Figure 10. Mass enthalpy as a function of temperature for the reaction in zone 2. 


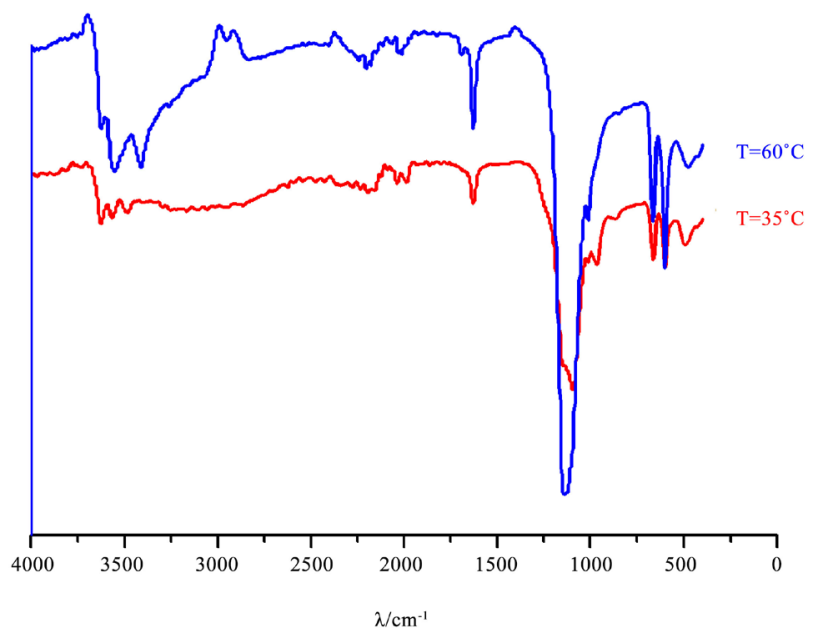

Figure 11. The IR spectra recorded of the residue obtained after attack for different temperatures in zone 2.

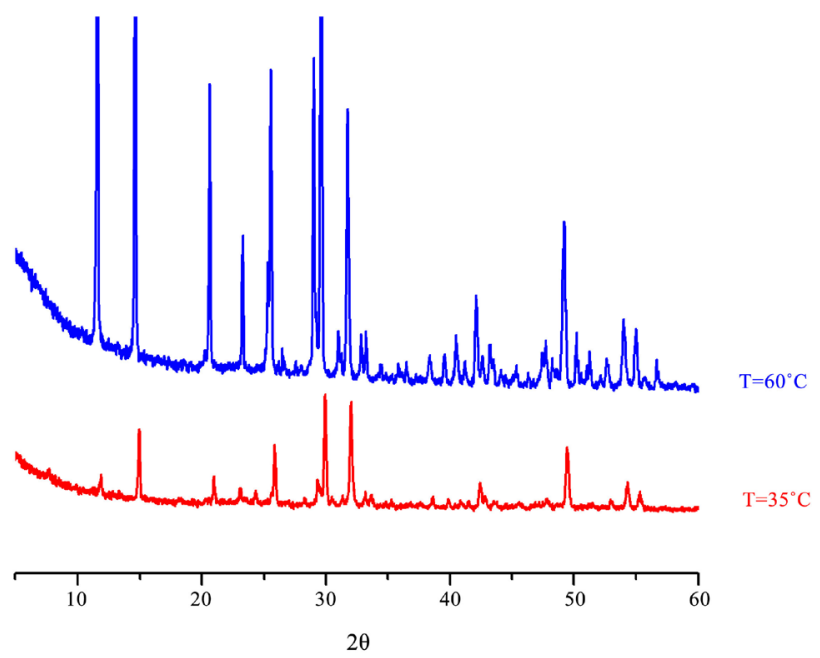

Figure 12. Diffractograms recorded of the residue obtained after attack for different temperatures in zone 2 .

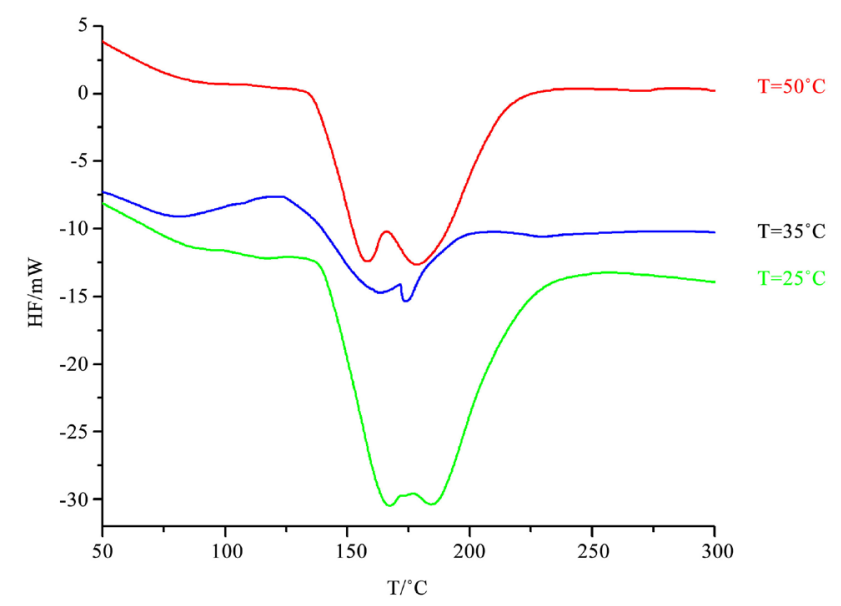

Figure 13. DSC curves registered of the residue obtained after attack for different temperatures in zone 2. 


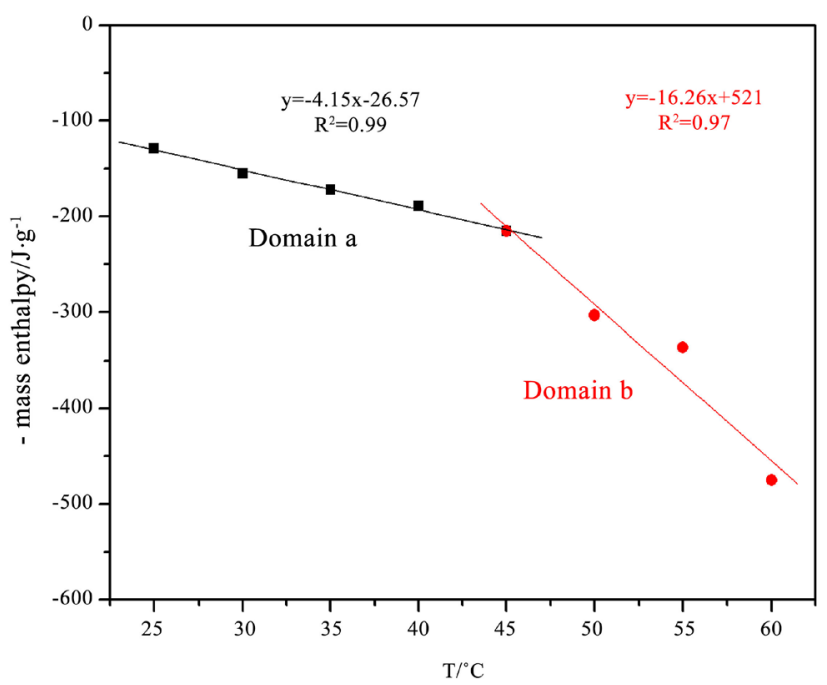

Figure 14. Mass enthalpy as a function of temperature for the reaction in zone 3.

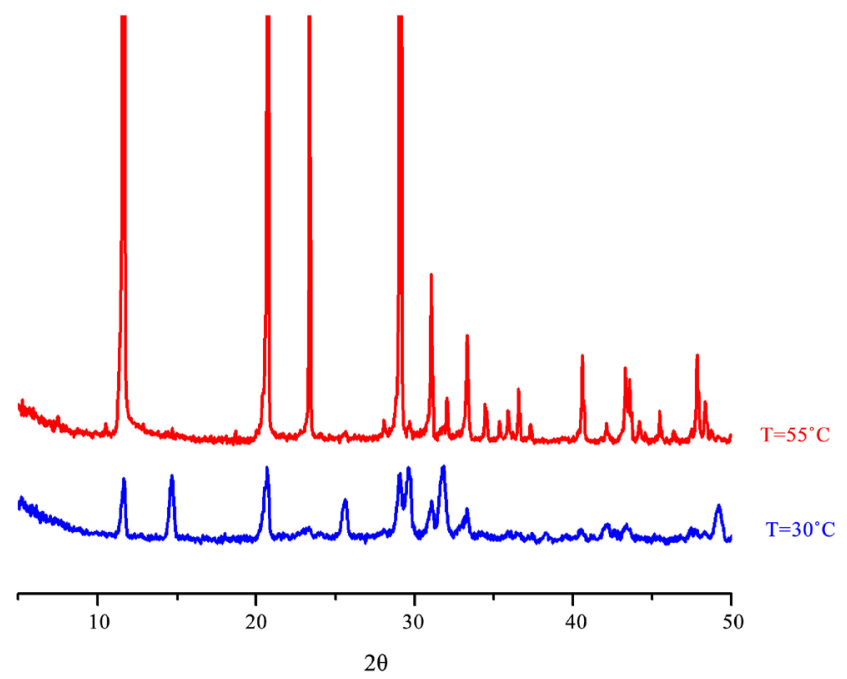

Figure 15. Diffractograms recorded of the residue obtained after attack for different temperatures in zone 3.

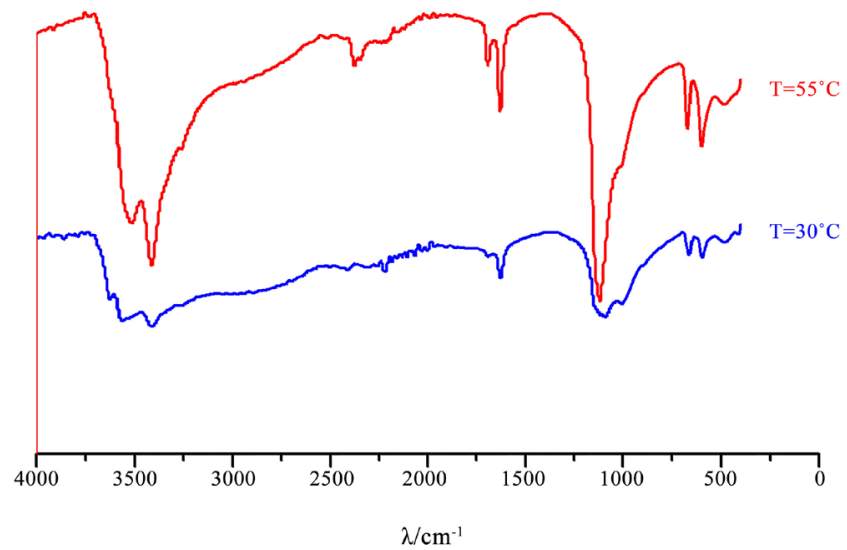

Figure 16. IR spectra recorded of the residue obtained after attack for different temperatures in zone 3. 


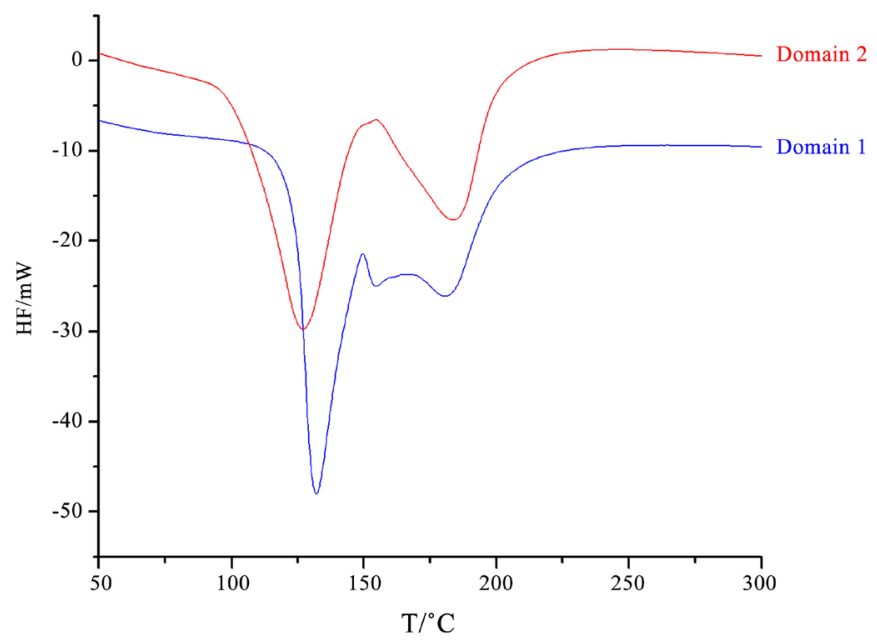

Figure 17. DSC curves registered of the residue obtained after attack for different temperatures in zone 3.

Several authors have reported that the temperature has an inverse effect on the rate of the attack reaction [30] [51] [52], in particular the work carried out by Yarstri. [52] and Abali [51]. For natural phosphates, these authors agree that at a temperature close to $40^{\circ} \mathrm{C}$, the rate of the attack reaction decreases as the temperature increases. According to our results, it seems that the effect of the temperature on the sulfo-phosphoric attack reaction on the NP generates a change of mechanism at around $45^{\circ} \mathrm{C}$ instead of decreasing the speed of the reaction. This result is in a good agreement with previous work on the effect of temperature on the dissolution reaction of a fluorapatite by phosphoric acid [11].

\section{Conclusion}

Attack of a phosphate ore by a mixture of sulfuric and phosphoric acid solution is a complex process beginning by dissolution of the ore and then precipitation of $\mathrm{DH}, \mathrm{HH}$ or a mixture of these two products. As a concluding remark, some works dealing with phosphate ore attack agree with a diminution of the reaction rate near $40^{\circ} \mathrm{C}$ when increasing temperature. Our results show rather a mechanism change at a temperature $45^{\circ} \mathrm{C}$.

\section{Conflicts of Interest}

The authors declare no conflicts of interest regarding the publication of this paper.

\section{References}

[1] Zafar, I.Z., Ansari, T.M., Ashraf, M. and Abid, M.A. (2006) Effect of Hydrochloric Acid on Leaching Behavior of Calcareous Phosphorites. Iranian Journal of Chemistry and Chemical Engineering, 25, 47-57.

[2] Lefires, H., Medini, H., Megriche, A. and Mgaidi, A. (2014) Dissolution of Calcareous Phosphate Rock from Gafsa (Tunisia) Using Dilute Phosphoric Acid Solution. 
International Journal of Nonferrous Metallurgy, 3, 1-7.

https://doi.org/10.4236/ijnm.2014.31001

[3] Lawer, J.E., Mc Clintock, W.O. and Snow, R.E. (1978) Beneficiation of Phosphate Rock. Review. Minerals Science and Engineering, 10, 278-294.

[4] Janikowski, M., Robinson, N. and Sheldrick, W.F. (1964) Insoluble Phosphate Losses in Phosphoric Acid Manufacture by the Wet Process: Theory and Experimental Technique. Presented at the 18th Meeting of Fertilizer Society, Vol. 81, 3-41.

[5] Elnashaie, S.S. and Al-Fraris, T.F. (1990) Investigation of Acidulation and Coating of Saudi Phosphate Rocks. Industrial \& Engineering Chemistry Research, 29, 2389-2401. https://doi.org/10.1021/ie00108a012

[6] Hsieh, S.S. (1987) Beneficiation of Dolomotic Phosphate Ores Using Modified Crago-TVA Process. Industrial \& Engineering Chemistry Research, 26, 1413-1419. https://doi.org/10.1021/ie00067a024

[7] Mostafa, S.I., Sadda, M.Y., Boulis, S.N. and Hawash, S.I. (1998) Flotation of Low Grade Siliceous Calcareous Phosphate Ore. Physicochem Probl Miner Process, 42, 5-16.

[8] Abbes, M., Ahmed, B., Noureddine, D., Rabah, R. and Salah, B. (2016) Obtaining the Partially Acidulated Phosphate Rocks by Means of Intermediate-Grade Phosphate and Diluted Phosphoric Acid: Influence of Some Parameters. Polish Journal of Chemical Technology, 18, 39-43. https://doi.org/10.1515/pjct-2016-0046

[9] Chihi, H., Khattech, I. and Jemal, M. (2016) Thermochemistry and Kinetics of the Attack of Magnesium-Carbonateco-Substituted Fluorapatites by Hydrochloric Acid at Different Temperatures (25-55) ${ }^{\circ} \mathrm{C}$. Journal of Thermal Analysis and Calorimetry.

[10] Dorozohkin, S.V. and Prakt, J. (1996) Dissolution Kinetics of Single Flourapatite Crystals in Phosphoric Acid Solution under the Conditions of the Wet-Process Phosphoric Acid Production. Journal für Praktische Chemie, 338, 620-626. https://doi.org/10.1002/prac.199633801119

[11] Brahim, K., Antar, K., Khattech, I. and Jemal, M. (2008) Etude thermodynamique et cinétique de l'attaque de la fluorapatite par l'acide phosphorique. Scientific Research and Essays, 3, 35-39.

[12] Brahim, K., Khattech, I., Dubés, J.P. and Jemal, M. (2005) Etude cinétique et thermodynamique de la dissolution de la fluorapatite dans l'acide phosphorique. Thermochimica Acta, 436, 43-50. https://doi.org/10.1016/j.tca.2005.06.019

[13] Brahim, K., Baatout, A.S., Khattech, I. and Jemal, M. (2017) Dissolution Kinetics of Fluorapatite in the Hydrochloric Acid Solution. Journal of Thermal Analysis and Calorimetry.

[14] Antar, K., Brahim, K. and Jemal, M. (2006) Etude cinétique et thermodynamique de l'attaque d'une fluorapatite par des mélanges d'acides sulfurique et phosphorique à $25^{\circ}$ C. Thermochimica Acta, 449, 35-41. https://doi.org/10.1016/j.tca.2006.07.011

[15] Antar, K. and Jemal, M. (2007) Kinetics and Thermodynamics of the Attack of Fluorapatite by a Mixture of Sulfuric and Phosphoric Acids at $55^{\circ} \mathrm{C}$. Thermochimica Acta, 452, 71-75. https://doi.org/10.1016/j.tca.2006.09.019

[16] Zendah, H., Khattech, I. and Jemal, M. (2013) Thermochemical and Kinetic Studies of the Acid Attack of B Type Carbonate Fluorapatites at Different Temperatures (25-55) ${ }^{\circ}$ C. Thermochimica Acta, 565, 46-51. https://doi.org/10.1016/j.tca.2013.04.033

[17] Guidry, M.W. and Mackenzie, F.T. (2003) Experimental Study of Ignous and Sedimentary Apatite Dissolution: Control of pH, Distance from Equilibrium, and Tem- 
perature on Dissolution Rates. Geochimica et Cosmochimica Acta, 67, 2949-2463. https://doi.org/10.1016/S0016-7037(03)00265-5

[18] Dorozhkin, S.V. (1997) Surface Reactions of Apatite Dissolution. Journal of Colloid and Interface Science, 191, 489-497. https://doi.org/10.1006/jcis.1997.4942

[19] Antar, K. and Jemal, M. (2008) Kinetics and Thermodynamics of the Attack of a Phosphate Ore by Acid Solutions at Different Temperatures. Thermochimica Acta, 474, 32-35. https://doi.org/10.1016/j.tca.2008.05.006

[20] Amira, B.S., Brahim, K., Khattech, I., Kamoun, L. and Jemal, M. (2016) Thermochemical and Kinetic Investigations of the Phosphoric Attack of Tunisian Phosphate Ore. Journal of Thermal Analysis and Calorimetry, 131, 3121-3132. https://doi.org/10.1007/s10973-017-6825-Z

[21] Chaabouni, A., Chtara, C., Nzihou, A. and El-Feki, H. (2013) Kinetic Study of the Dissolution of Tunisian Natural Phosphate or Francolite Inindustrial Phosphoric Acid. Journal of Advances in Chemistry, 6, 908-916. https://doi.org/10.24297/jac.v6i1.6585

[22] Ben Brahim, F., Mgaidi, M. and El Maaoui, M. (1999) Kinetics of Leaching of Tunisian Phosphate ore Particles in Dilute Phosphoric Acid Solutions. The Canadian Journal of Chemical Engineering, 77, 136-142. https://doi.org/10.1002/cjce.5450770123

[23] Amira, B.S., Ibrahim, K., Khattech, I. and Jemal, M. (2016) Attack of Tunisian Phosphate Ore by Phosphoric Acid. Thermal Analysis and Calorimetry. Journal of Thermal Analysis and Calorimetry, 124, 1671-1678. https://doi.org/10.1007/s10973-016-5263-7

[24] Ashraf, M., Iqbal-Zafar, Z. and Ansari, T. (2005) Selective Leaching Kinetics and Upgrading of Low-Grade Calcareous Phosphate Rock in Succinic Acid. Hydrometallurgy, 80, 286-292. https://doi.org/10.1016/j.hydromet.2005.09.001

[25] Gharabaghi, M., Irannajad, M. and Noaparast, M. (2010) A Review of the Beneficiation of Calcareous Phosphate Ores Using Organic Acid Leaching. Hydrometallurgy, 103, 96-107. https://doi.org/10.1016/j.hydromet.2010.03.002

[26] Aly, H.F., Ali, M.M. and Taha, M.H. (2013) Dissolution Kinetics of Western Desert Phosphate Rocks, Abu Tartur with Hydrochloric Acid. Arab Journal of Nuclear Sciences and Applications, 46, 1-16.

[27] Olenipekun, E.O. (1999) Kinetics of Dissolution of Phosphorite in Acid Mixtures. Bulletin of the Chemical Society of Ethiopia, 13, 63-70. https://doi.org/10.4314/bcse.v13i1.21057

[28] Mizane, A. and Louhi, A. (2007) Comparative Study of the Dissolution of Phosphate Rock of DjebelOnk (Algéria) by the Nitric Acid and Sulfuric Acid. Journal of Applied Science, Engineering and Technology, 2, 1016-1019.

[29] Sınırkaya, M., Özer, A.K. and Gülaboğlu, M.Ş. (2014) Investigation of the Solubilities of Sulfated and Ground Phosphate Rock after Sulfation in $\mathrm{H}_{2} \mathrm{SO}_{4}$ Solution. Pamukkale Üniversitesi Mühendislik Bilimleri Dergisi, 20, 253-257.

[30] Sevim, F., Saraç, H. and Yartasi, A. (2003) Dissolution Kinetics of Phosphate Ore in $\mathrm{H}_{2} \mathrm{SO}_{4}$ Solution. Industrial \& Engineering Chemistry Research, 42, 2052-2057. https://doi.org/10.1021/ie0201680

[31] Lassis, M., Mizane, A., Dadda, N. and Rehamnia, R. (2015) Dissolution of DjebelOnk Phosphate Ore Using Sulfuric Acid. Environmental Nanotechnology, Monitoring \& Management, 4, 12-16. https://doi.org/10.1016/j.enmm.2015.03.002

[32] Mizane, A. and Louhi, A. (2008) Calcination Effects on Sulfuric Dissolution of 
Phosphate Extracted from DjebelOnk Mine (Algéria). Asian Journal of Chemistry, 20, 711-717.

[33] Fariss, T.F., Elnashaie, S.S.E.H., Abdel-Razik, S.M., Abdel-Aleem, F.A. and Ibrahim, H.A. (1991) Comparison between Acidulation by Sulphuric Acid and by Phosphoric Acid for Saudi Phosphate Rock. Fertilizer Research, 29, 209-227. https://doi.org/10.1007/BF01048962

[34] Gilbert, R.L. and Moreno, E.C. (1965) Dissolution of Phosphate Rock by Mixtures of Sulfuric and Phosphoric Acids. Industrial \& Engineering Chemistry Process Design and Development, 4, 368-371. https://doi.org/10.1021/i260016a006

[35] Jamialahmadi, M. and Emam, S.H. (1998) Dissolution of Phosphate Rock by Mixtures of Sulfuric and Phosphoric Acid. Developments in Chemical Engineering and Mineral Processing, 6, 273-293. https://doi.org/10.1002/apj.5500060503

[36] Frikha, N., Hmercha, A. and Gabsi, S. (2014) Modelling of a Solid Dissolution in Liquid with Chemical Reaction: Application to the Attack Reaction of Phosphate by Sulphuric Acid. The Canadian Journal of Chemical Engineering, 92, 1829-1838. https://doi.org/10.1002/cjce.21986

[37] Calmanovici, C.E., Gilot, B. and Laguerie, C. (1997) Mechanism and Kinetics for the Dissolution of Apatitic Materials in Acid Solutions. Brazilian Journal of Chemical Engineering, 14, 95. https://doi.org/10.1590/S0104-66321997000200001

[38] Sluis, S.V., Meszaros, Y., Gerda, M. and Rosmalen, V. (1987) The Digestion of Phosphate ore in Phosphoric Acid. Industrial \& Engineering Chemistry Research, 26, 2501-2505. https://doi.org/10.1021/ie00072a020

[39] Huffmann, E.O., Cate, W.E., Deming, M.E. and Elmore, K. (1957) Rates of Solution of Calcium Posphates in Phosphoric Acid Solution. Journal of Agricultural and Food Chemistry, 5, 266-275. https://doi.org/10.1021/jf60074a001

[40] Amira, S.B., Hichri, M., Bechrifa, A. and Khattech, I. (2014) Test and Calibration Processes for the Differential Reaction Calorimeter (DRC): Application: Dissolution of Calcium Fluorapatite in the Hydrochloric Acid. Thermochimica Acta, 580, 85-92. https://doi.org/10.1016/j.tca.2014.02.006

[41] Abdel-Aal, E.A., Rashed, M.M. and El-Shall, H. (2004) Crystallization of Calcium Dehydrate at Different Supersaturation Ratios and Different Free Sulphate Concentrations. Crystal Research and Technology, 39, 313-321. https://doi.org/10.1002/crat.200310188

[42] Putnis, A., Winkler, B. and Fernandez-Diaz, L. (1990) In Situ IR Spectroscopic and Thermogravimetric Study of the Dehydration of Gypsum. Mineralogical Magazine, 54, 123-128. https://doi.org/10.1180/minmag.1990.054.374.14

[43] Kanesaka, I. and Oda, K. (1995) Infrared Study on T-Beta-Radiolysis in the Ca$\mathrm{SO}_{4}-0.5 \mathrm{H}_{2} \mathrm{O}-\mathrm{T}_{2} \mathrm{O}$ System. Spectrochimica Acta, 51, 941-945. https://doi.org/10.1016/0584-8539(94)00234-3

[44] Guan, B., Jiang, G., Wu, Z., Mao, J. and Kong, B. (2011) Preparation of $\alpha$-Calcium Sulfate Hemihydrate from Calcium Sulfate Dihydrate in Methanol-Water Solution under Mild Conditions. Journal of the American Ceramic Society, 94, 3261-3266. https://doi.org/10.1111/j.1551-2916.2011.04470.x

[45] Valimbe, P.S. and Malhotra, V.M. (2002) Effects of Water Content and Temperature on the Crystallization Behavior of FGD Scrubber Sludge. Fuel, 81, 1297-1304. https://doi.org/10.1016/S0016-2361(02)00045-5

[46] James, C.R. (1972) Thermal Analysis of Calcium Sulfate Dihydrate and Supposed $\alpha$ and $\beta$ Forms of Calcium Sulfate Hemihydrate from 25 to $500^{\circ} \mathrm{C}$. Journal of research 
of the National Bureau of Standards, 76, 41-49.

[47] El Cadi, A., FakihLanjri, A., Lalilti, A., Chouaibi, N., Asskali, A. and Khaddor, M. (2014) Caractérisation de la fraction lipidique du phosphogypse: Origine et évaluation du degré de transformation des polluants organiques (Characterization of the Lipid Fraction of Phosphogypsum: Origin and Assessment of the Degree of Transformation of Organic Pollutants). Journal of Materials and Environmental Science, 5, 2223-2229.

[48] Ben Mansour, M., Cherif, A.S. and Ben Jabrallah, S. (2013) Thermal Characterization of a Tunisian Gypsum Plaster as Construction Material. Energy Procedia, 42, 680-688. https://doi.org/10.1016/j.egypro.2013.11.070

[49] Violeta, L. (2013) $\alpha$-Hemihydrate Gypsum from Flue Gas Desulphurization Gypsum. Materials Science-Medziagotyra, 19, 197-202.

[50] Ostroff, A.G. (1964) Conversion of Gypsum to Anhydrite in Aqueous Salt Solutions. Geochimica et Cosmochimica Acta, 28, 1363-1372. https://doi.org/10.1016/0016-7037(64)90154-1

[51] Abali, Y., Colak, S. and Yarstri, A. (1997) Dissolution Kinetics of Phosphate Rock with $\mathrm{Cl}_{2}$ Gas in Water. Hydrometallurgy, 46, 13-25. https://doi.org/10.1016/S0304-386X(96)00094-1

[52] Yarstri, A., Kocakerim, M., Yapici, S. and Ozmetin, C. (1994) Dissolution Kinetics of Phosphate Ore in $\mathrm{SO}^{2-}$ Saturated Water. Industrial \& Engineering Chemistry Research, 33, 2220-2225. https://doi.org/10.1021/ie00033a028 